\title{
'I know I will hear what I heard before:' The Role of Music in Narrative Progression
}

\author{
Andrea Pérez Mukdsi \\ University of North Georgia, U.S.A. Orcid ID oooo-0oo3-3922-1073. Andrea. \\ Email: PerezMukdsi@ung.edu
}

Received November 01, 2017; Accepted March 25, 2018; Published May 24, 2018.

\begin{abstract}
This article constitutes an initial approach to the analysis of musical instances as narrative progressionrelated marks. For this purpose, I examine the short "Meeting" (1966) by the Argentine writer Julio Cortázar using the notions of instability and tension coined by James Phelan. I show in what way the story-discourse model of these texts uses various musical elements that produce a high/low degree of character presence/reader immediacy within the narrative progression. Ambiguity represents one of Cortázar's characteristic traits, due to the fact that instabilities are seldom resolved in the story and tensions are left to the reader's empathetic constructions. I argue that the musical material that either motivates or comes forth from this text is the force that shifts the narrative away from ambiguities and propels the character and reader forward through the absence of closure and completeness that is frequent in most Cortázar's narratives.
\end{abstract}

Keywords: Julio Cortázar, Mozart, music, narratology

\section{Introduction}

Back in the 196os, Julio Cortázar's texts started exposing the diversity of games that narrative can play with the latent properties in its medium. In fact, his most famous work Hopscotch expanded the novel's expressive potential beyond conventional practice and became a canonical work in Latin America's new narrative. An exhaustive analysis Cortázar's literary production has showed me that much of his fiction lies at the intersection between language and music. In many of his writings, Cortázar's textual dynamics calls the audience to follow not only textual cues but also musical gestures. The result in readerly dynamics is precisely what I have labeled contrapuntal narrative. Contrapuntal narrative is the result of simultaneous reading across (at least two) different artistic discourses and along vertical and horizontal axes within the storyworld. ${ }^{2}$

In this article, I describe my approach to the analysis of musical instances as narrative progression-related marks in Julio Cortázar's literary works. I present the analysis of "Meeting" ("Reunión") a short story published in 1966. In the spirit of James Phelan's view of narrative progression, I will use the notions of instability and tension to argue that the musical material that either motivates or comes forth from these texts is the force that shifts the narrative away from ambiguities and propels the character and reader forward through the frequent absence of closure and completeness that is representative of Cortázar's texts.

"Axolotl" and "Night Face Up" are two well-known short stories that provide a great

(c) AesthetixMS 2018. This Open Access article is published under a Creative Commons Attribution Non-Commercial 4.0 International License (http://creativecommons.org/licenses/by-nc/4.o/), which permits non-commercial re-use, distribution, and reproduction in any medium, provided the original work is properly cited. For citation use the DOI. For commercial re-use, please contact editor@rupkatha.com. 
example of the Argentine author's use of duality and contradiction. They create in the reader a recurring sense of binary opposition similar to the two sides of a coin. In the former, glass divides the two territories associated to the axolotl: the inside and outside of the reptile's cage. In the latter, "Night Face Up", sleep represents the delicate frontier between the protagonist's hospital bed and the victim of an ancient Moteca ritual of sacrifice. Likewise, "House Taken Over" contains, on the one hand, the reality of two conservative brothers in Buenos Aires, and on the other, a world of mysterious occupants who will progressively invade the entire house. In these, as in many others of his well-known short stories, Cortázar reveals two opposed realms. This dual universe has been interpreted as a contestatory relationship between the Hispanic tradition and Cortázar's innovative narratives. Rather than exploring these issues, my analysis focuses on the many ways in which the music within Cortázar's text influences the reader's perception of the narrative progression. In fact, my view of Cortázar's approach to narrative progression is a rhetorical one that attends both to textual dynamics and to the developing responses of the audience to those dynamics. By using James Phelan's take on narrative progression, I suggest that the music within the text not only propels the reader forward but also provides him with a new sense of completeness.

By calling attention to the musical elements in Cortázar's craft that tend to be overlooked within the more ideological and cultural readings, I also hope that this essay can suggest the benefits of renewed attention to questions of readerly dynamics in his production, what Cortázar himself has called reader 'complicity.'

\section{Music and Narrative Instabilities}

In "Axolotl," "Night Face Up," or "House Taken Over," the storyworld install a clear polarity that offers the reader no way out. Instead, "Meeting," allows the reader to negotiate various obstacles within textual dynamics. The short story I will examine today, as well as "The Gates of Heaven" (1951), "The Menades" (1956), and "Circe" (1951) have in common the use of music as a narrative device. I suggest that the presence of music shifts the narrative away from plot dualities, so common in Cortázar's writing. Or, in Phelan's words, the presence of musical material pushes the progression beyond the story global instabilities giving a new perspective to the notion of completeness.

In 1989 James Phelan defined two kinds of unstable relationships generated by a text: those generated between characters - instabilities - and those established between implied author and reader - tensions. ${ }^{3}$ In addition, he makes a distinction between global instabilities (those lasting for more than two scenes, accumulating complication at later stages) and local instabilities (those lasting for one or two scenes and resolving quickly). According to this author, "global instabilities are those that provide the main track of the progression and must be resolved for a narrative to attain completeness." ${ }^{4}$ Not all the narratives seek the completeness of global instabilities. In fact, Cortázar's short stories are particularly known for not resolving them. Cortázar's authorial audience appreciates the unstable relationships within textual dynamics, and therefore expects that global instabilities and tensions might never be resolved. However, in this essay, I argue that those stories containing musical material affect readerly response in many ways, the most important being the capacity of coping with instabilities and tensions.

"Meeting" is one of Cortazar's early short stories. It is a fictional account of a guerrilla battle as told by a Latin American revolutionary leader lost in a labyrinthic tropical forest. The protagonist, suffocated by his asthma, attempts to makes his way through the lush vegetation 
together with his companions. In the middle of their dramatic struggle for survival, we learn that the dramatized narrator is looking for his comrade Luis. Luis' whereabouts are unknown. The search adds anxiety to the difficulties proper of the oppressing reality that surrounds the protagonist. All the surroundings are an obstacle to finding a path out to a calm daily reality. The effects of the violent experience create in the protagonist an internal split. He is constantly torn between two worlds: the immediate one (the war) and the one he longs for (the simplicity of everyday life). However, the turmoil of death and the blistering heat do not prevent him from navigating through the melodies that return to his memory while crossing the jungle:

It does me well to remember a theme by Mozart that has accompanied me for ever, the initial movement of the quartet "Die Jagd," the evocation of the halalí in the calm voice of the violins [...] I think about it, I repeat it, I sing it softly in my memory, and I feel at the same time how the melodies and the treetops against the sky become friends [...] until the picture is organized by the presence of the melody. (p. 553)

This last phrase gives us a glimpse of the influence of rhythm and melody over the hostile world that threatens the narrator. Mozart's string quartet "Die Jagd" manages to reconcile the chaos of the ongoing combat with the hope for a simple life. Through the presence of music, the implied author opens a bridge that communicates two opposed worlds and by doing so, he builds a contention structure that holds the character together beyond any global instability.

Towards the end, the protagonist reunites with his friend Luis. In the last paragraph, when looking at the treetops once again, the melody initiates the narrator into Mozart's second movement, the "Adagio."

At the end, I said nothing to him, but I felt we where entering the adagio of the quartet, in the precarious plenitude of a few hours [...] However, it was enough to look at the treetops to feel that the willpower was arranging their chaos, it was imposing the chaos the drawing of the adagio that would sometime enter the final allegro [...] the leaves and the branches were slowly surrendering to my wishes, they were my melody; Luis' melody, who continued to talk, unaware of my fantasy, and afterwards I saw a star engrave itself in the middle of the drawing, and it was a small star and very blue star, and even though I know nothing about astronomy and I could not tell if it was a star or a planet, I was sure that it was not Mars or Mercury, it was too shiny in the middle of the Adagio, too much in the center of Luis' words to be confused with Mars or Mercury. (p. 581)

This quote shows the protagonist embarking on Mozart's music. His ideas jump on the instrumental lines and climb the trees; ideas and melodies reach the sky beyond the treetops. The sounds of Mozart's work expand the narrative space: through the text we perceive trees and sky following the outline of the musical discourse in the adagio. In addition, our perception of narrative time is affected by other parameters. Time, essential to musical discourse, meets space when the adagio becomes a canvas containing a blue star in its center: the music turns out to be a pictorial device shaping the narrative. Music and painting are juxtaposed. Likewise, both characters are immersed in the internal vertigo produced by the radical opposition between war and peace. That opposition will not be resolved in the narrative. In Phelan's terms, global instabilities do not resolve within plot dynamics. However, those chords and musical lines that play in the mind of the protagonist manage to make compatible all opposing elements, such as present and future, reality and dream. There is no resolution to any of the conflicts in the storyworld. Nevertheless, the musical material opens the text to suggest multiple layers of meaning, and releasing the character from his oppressive environment. Music gives the character 
new lenses through which to look at conflict. It is precisely the musical discourse that expels the character from the distress of war and yearning of home. The new textual dynamics derived from the musical-factual counterpoint softens the tension of global instabilities.

If completeness must be attained to fulfill narrative needs, such result should not be limited to plot related conflicts (instabilities). First, the mix generic modes and transdisciplinary production that we see appearing in countless ways in contemporary narrative provide an opportunity for a critical reexamination of the notion. Secondly, not all media offer the same resources when it comes to narrative progression. For instance, language cannot display continuous processes unless it segments time into discrete moments. On the contrary, music can capture the flow of time in pure form. In "Meeting," the migration of narrative from literary discourse to musical discourse does not present cognitive challenges, because a core idea - if not more - travels across the different media. Additionally, its narrative potential is filled out and actualized differently when the story reaches the music realm. Therefore, I propose a broader sense of completeness, one that includes the possibility of creating other modes of sense-making throughout the text during narrative progression. The expansion of such notion allows each textual dynamics to build a particular fulfillment mechanism. In "Meeting," as well as in many other Cortázar's literary works, different evocations of musical pieces work as thematic "intertexts" proposing a new set of sense-making parameters, all of which have music as a crucial component. That being said, I argue that progression-related segments in "Meeting," become a score intertwining music and events. Such score is to be traversed contrapuntistically: listening to all narrative components - not only plot-related ones - without loosing sight of the overall progression. Completeness within textual dynamics is therefore achieved not by resolving story instabilities - such as anxiety, war, illness, longing - but by adjusting to them and accepting them as voices that determine the overall score structure. How does the character accomplish such endeavor? By simply embarking in the music, adopting its contrapuntal view, and transforming it from a musical analogy to his philosophy of life.

In "Meeting," the music enables the two friends to escape the contradictions that populate the storyworld and to proceed, beyond all textual instabilities, into the final "Allegro." But there is more to the effect of musical discourse than the reorganization in the narrative's internal dynamics: the audience is actively involved in the shift produced in the text through Mozart's work by successfully negotiating the given narrative tensions. With the help of Mozart's sounds, the reader is able to cope with the frequent absence of closure and completeness that characterizes Cortázar's writings.

Let us explore some of the mechanics that lie beneath this process. Phelan (2008:197) remind us that, according to Peter Rabinowitz "beginnings not only set the narrative in motion but also give it a particular direction." I would add that beginnings set the particular way in which the progression moves. In fact, audiences perceive such direction as soon as the story's global instabilities start to unfold. That is why beginnings become a crucial component of our entry into the narrative world. In "Meeting," the presence of music appears as intrinsically related to textual dynamics from the start. Mozart's string quartet constantly permeates time and space inviting the audience to shift the attention away from the instabilities generated by the plot. The musical intervention sets a mechanism affecting not only textual dynamics but also the audience's understanding of the text. Let's say that, because of the perceived dependence of the progression on Mozart's work, our configuration of the storyworld will be necessarily affected by and tied to the music: its rhythm, its particular way of coping with contradiction, and its capacity of arousing emotion. 
Beyond the opening section, the audience of "Meeting" ignores what to expect with respect to the chaos surrounding the protagonist. Like him, we immediately join the music flow. Our attention is not on whether the ceasefire will occur, or if the main character will find his way out of his anxiety, but on being immersed in the flow of sound and images that has proven an antidote to madness. It is precisely the melodic lines that subtlety accompany the discourse since the onset, that create in us the perception of stability completely absent in the story dynamics due to the lack of closure in the events. Thus, while the author is of course working with a plot, what matters to us most are the promises of keeping the progression running through the music material. Through juxtapositions of emotions, facts and musical evocations the discourse in "Meeting" proposes a contrapuntal reading: longing and melodies, battle and violins, trees and chords lead us by the hand to it. Cortázar keeps us focused on a narrative progression that is built on a complex textual dynamics derived from the musical-factual counterpoint and not only on plot-related cues. I propose that Cortázar succeeds in stimulating the audience complicity through the musical language that is intertwined in the text. We clearly perceive this mechanism at the point of greatest complication in the plot. Returning to our second quote/excerpt, we notice that the discourse moves steadily in order to maintain the audience's interest in the rhythm of the pilgrimage in the jungle, a pilgrimage embedded in Mozart's "Die Jagd."

By incorporating the musical discourse since the opening of "Meeting," Cortázar's audience is invited to accept it as an inherent part of the narrative discourse. Not only do we infer that the presence of music is closely connected to the character's exhausting journey, but also that its presence provides a satisfactory palliative to narrative tensions. Consequently, this intuition acts as tacit knowledge that strongly affects our understanding of every sentence of the narrative, and helps us negotiate the unstable relationships produced by the text.

Viewed through the lenses of this model, with "Meeting" Cortázar develops a radical experiment with narrative tensions and readerly response through the use of music. This is also true for other short stories like "The Gates of Heaven," “The Menades," "Circe," and "Clone," as well as for central chapters in Hopscotch and A Certain Lucas (1979). In all these works, the audience's primary focus is deviated from plot-related markings by means of the music discourse. None of their protagonists suffer a transformation; none of them can modify their reality. Local instabilities hardly ever achieve a solution. As well as in "Meeting," these work's 'accomplice' audience redefines textual and readerly dynamics while contrapuntal narrative becomes the solution overcome any tension between the text and the reader. Eager to make connections between music and literature, scholars have related the presence of jazz in Cortázar's writings to identity and the alienation of an artist from his transient locations. However, I am convinced that musical elements in his works matter to the readerly response because they intrinsically modify our understanding of the narrative world, and its effects are immediate to the reading experience. Music as a communicative gesture imposes on the audience a particular way of articulating perceptual and conceptual information, creating a dominant interpretative paradigm from the very beginning of the narrative. As seen today, such paradigm acquires value as the progression advances. In turn, the contrapuntal narrative paradigm influences the audience's acceptance of contradictions and in-completeness of the action, including our initial generic identification of the narrative and the expectations that follow from that identification. Therefore, I propose that the music within Cortázar's literary production has the ultimate goal of satisfying the reader's expectations for completeness while moving him forward, beyond all possible textual instabilities and tensions. 


\section{Endnotes}

${ }^{1}$ I base the notion of contrapuntal narrative on Said's concept of contrapuntal reading, which was influenced by his deep love of Western music. Counterpoint is a compositional procedure of western classical music where various contrasting themes interact with only a provisional privilege being given to any particular one; yet in the resulting polyphony there is harmony and order. Likewise, I address Cortázar's narratives as a contrapuntal unit, where an organized interplay derives from considering all contradictory elements simultaneously, including different artistic media. It is the purpose of my study to show to what extend the intervention of musical material creates the conditions for contrapuntal narrative by inviting the reader to explore textual dynamics across media and to integrate all apparent ambiguities in the storyworld.

${ }^{2}$ The notion of storyworld, as coined by David Herman in his book Story Logic (2002), refers to the mental models through which readers reconstruct the world evoked implicitly as well as explicitly by a narrative. In a later publication, Herman (2009: 72-73) defines the term as "global mental representations enabling interpreters to frame inferences about the situations, characters, and occurrences either explicitly mentioned in or implied by a narrative text or discourse. As such, storyworlds are mental models of the situations and events being recounted - of who did what to and with whom, when, where, why, and in what manner. Reciprocally, narrative artifacts (texts, films, etc.) provide blueprints for the creation and modification of such mentally configured story worlds."

${ }^{3}$ Phelan (1989: 15), differentiates "two main kinds of instabilities: the first are those occurring within the story, instabilities between characters, created by situations, and complicated and resolved through actions. The second are those created by the discourse, instabilities-of value, belief, opinion, knowledge, expectation-between authors and/or narrators, on the one hand, and the authorial audience on the other." In order to make the distinction easier, he calls "instabilities" those unstable relations within the story, while using "tension" when referring to those between the author/narrator and the audience. For details about authorial audience, see Peter Rabinowitz (1977: 121-141).

${ }^{4}$ While "local instabilities are those whose resolution does not signal the completeness of the progression."

${ }^{5}$ All translations from Spanish are mine, unless noted.

\section{Citations and References}

Cortázar, J. (2003). Obras Completas I (Vol. I). Barcelona: Opera Mundi.

Herman, D. (2002). Story Logic: Problems and Possibilities of Narrative. Lincoln: University of Nebraska Press.

Herman, D. (2009). Narrative ways of worldmaking. In S. Heinan and R. Sommer (Eds.), Narratology in the age of cross-disciplinary narrative research. (pp. 71-87). Berlin, DE: Walter De Gruyter.

Phelan, J. (1989). Reading People, Reading Plots: Character, Progression, and the Interpretation of Narrative. Chicago: The University of Chicago Press.

Phelan, J. (2008). The beginning of Beloved: A rhetorical approach. In B. Richardson (Eds.), Narrative Beginnings: Theories and Practices. (pp. 195-212). Lincoln: University of Nebraska Press.

Rabinowitz, P. (1977). Truth in Fiction: A Reexamination of Audiences. Critical Inquiry, 4 (1977), 121-141.

Rabinowitz, P. (2002). Reading beginnings and endings. In B. Richardson (Eds.), Narrative Dynamics: Essays on Time, Plot. Closure, and Frames. (pp. 300-313). Columbus: Ohio State University Press.

Said, E. (1993). Culture and Imperialism. London: Vintage Press. 